\title{
Trends in socioeconomic health inequalities in the Netherlands, 1981-1999
}

\author{
J A A Dalstra, A E Kunst, J J M Geurts, F J M Frenken, J P Mackenbach
}

J Epidemiol Community Health 2002;56:927-934

\begin{abstract}
Study objective: To determine changes in socioeconomic inequalities in self reported health in both the 1980s and the 1990s in the Netherlands.

Design: Analysis of trends in socioeconomic health inequalities during the last decades of the 20th century were made using data from the Health Interview Survey (Nethhis) and the subsequent Permanent Survey on Living Conditions (POLS) from Statistics Netherlands. Socioeconomic inequalities in self assessed health, short-term disabilities during the past 14 days, long term health problems and chronic diseases were studied in relation to both educational level and household income. Trends from 1981 to 1999 were studied using summary indices for both the relative and absolute size of socioeconomic inequalities in health.

Setting: The Netherlands.

Participants: For the period 1981-1999 per year a random sample of about 7000 respondents of 18 years and older from the non-institutionalised population. Main results: Socioeconomic inequalities in self assessed health showed a fairly consistent increase over time. Socioeconomic inequalities in the other health indicators were more or less stable over time. In no case did socioeconomic inequalities in health seemed to have decreased over time. Socioeconomic inequalities in self assessed health increased both in the 1980s and the 1990s. This increase was more pronounced for income (as compared with education) and for women (as compared with men).

Conclusion: There are several possible explanations for the fact that, in addition to stable health inequalities in general, income related inequalities in some health indicators increased in the Netherlands, especially in the early 1990s. Most influential were perhaps selection effects, related to changing labour market policies in the Netherlands. The fact that the health inequalities did not decrease over recent years underscores the necessity of policies that explicitly aim to tackle these inequalities.
\end{abstract}

See end of article for authors' affiliations

Correspondence to: Dr J Dalstra, Department of Public Health, Erasmus University Rotterdam, PO Box 1738, 3000 DR Rotterdam, Netherlands; dalstra@mgz.fgg.eur.nl

Accepted for publication 14 March 2002

g t has often been shown that people of lower socioeconomic groups more often suffer from ill health. Much less is known about the changes over time in health inequalities between socioeconomic groups. For various reasons, it is important to study these changes. Firstly, for setting priorities in the field of public health it is important to know whether health inequalities are widening or decreasing. Secondly, it is important to know whether socioeconomic inequalities in health change to evaluate policies aimed at reducing these differences. Thirdly, studying the changes in socioeconomic health inequalities is a way to better understand the background of these inequalities, for example, to determine the sensitivity of health inequalities to changes in the relative income of different socioeconomic groups. Finally, analyses of past trends are necessary for making predictions of future trends in inequalities in health.

Most studies on trends in socioeconomic health inequalities have analysed mortality data. There has been comparatively little research on trends in socioeconomic inequalities in morbidity indicators like self reported health. Most studies on trends in inequalities in self reported health looked at self assessed health. ${ }^{1-9}$ There are only a few studies on trends in health inequalities in self reported health that look at other health indicators like limiting longstanding illness, ${ }^{4-610}$ chronic diseases, ${ }^{811}$ and short-term limitation during the past 14 days. $^{8911}$

The literature on trends in socioeconomic inequalities in self assessed health has produced inconsistent results. For example, the results concerning self assessed health are contrasting. Inequalities in self assessed health between socioeconomic groups have narrowed or remained about stable according to most studies. ${ }^{13-68}$ However, according to other studies these inequalities tended to widen. ${ }^{25}$ One study first showed a widening and then a narrowing of socioeconomic differences in self assessed health. ${ }^{7}$ These trends could also differ somewhat between men and women. A few studies indicated that socioeconomic health inequalities remained about the same for women while they narrowed for men. ${ }^{1346}$

The evidence on trends in socioeconomic inequalities in self assessed health is not only inconsistent but also fragmentary. Firstly, most studies only used one of the core socioeconomic indicators (education, occupational class, and income).2-467 Secondly, the timespan of studies on trends in socioeconomic inequalities in self assessed health varied considerably: some have used data from only a few years out of a longer time span. ${ }^{24-6}$ There are also studies that cover a period of 10 years ${ }^{7}$ or even between 15 and 20 years. ${ }^{13}$ Thirdly, different upper and lower age limits were used in studies on trends in inequalities in self assessed health. ${ }^{1356}$ It should finally be noted that most of the internationally published studies come from Finland and a few other countries such as Sweden and Britain. ${ }^{13-7}$ For the Netherlands, for example, only a few studies are published on trends in socioeconomic health inequalities in self assessed health. ${ }^{29}$ It is however interesting to study these trends for the Netherlands as it has been a fairly stable country. There was no strong economic recession like in Finland and Sweden in the early 1990s or a strong increase in income inequalities like in Britain. $^{4512}$

In summary, studies on trends in inequalities in self assessed health show contrasting results. In addition, the literature is still highly fragmentary. This study aimed to fill part of the many gaps. We used data from an ongoing national 
health survey: the Health Interview Survey (NethHIS), ${ }^{13}{ }^{14}$ which allowed us to construct a comprehensive overview on trends in socioeconomic inequalities in self reported health in the Netherlands. Firstly, we used both education and income as socioeconomic indicators. Secondly, four indicators of self reported health were used: self assessed health, short-term limitations during the past 14 days, long term health problems, and chronic diseases. Finally, we covered a period of 19 years ranging from 1981 until 1999. Altogether this made it possible to compare the results between different health and socioeconomic indicators, and to compare the trends in health inequalities in self reported health during the 1980s to more recent trends during the 1990s.

The following research questions are investigated in this paper. (1) Is there a decrease or increase in the size of socioeconomic health inequalities in self reported health between 1981-1999 in the Netherlands? (2) Is the trend during the 1990s the same as during the 1980s? (3) Are the observed trends consistent for both education and income, for both men and women and for all the above mentioned four health indicators?

\section{METHODS}

\section{Data source}

The data were derived from an ongoing national health survey: the Health Interview Survey (NethHIS). This survey is carried out by Statistics Netherlands (NCBS). ${ }^{13}{ }^{14}$ This survey started in 1981 and is conducted each year among a random sample of nearly 10000 respondents from the noninstitutionalised population in the Netherlands. This resulted in a representative sample of the non-institutionalised Dutch population. The information from this survey is mainly gathered during face to face interviews. These surveys were held throughout the whole year and took place at the homes of the respondents. The surveys were held in Dutch among persons registered at the municipal population registries.The health survey contains questions on a number of health indicators and socioeconomic indicators.

The Health Interview Survey changed into the Permanent Research on Living Conditions (POLS) in 1997. ${ }^{15}$ The important changes are that, since the introduction of the POLS, what used to be different surveys in the Netherlands were integrated into one system of level of living studies, and that with the introduction of the POLS proxy interviews were no longer held.

The non-response rate was $32 \%$ in 1981 and increased to $44 \%$ in 1999. In the discussion section, we will answer the question to what extent this problem may have biased the results.

For this study, we analysed data from the NethHIS and the POLS for the years 1981 until 1999 for all respondents aged 18 years and older.

\section{Health indicators}

For this study, four commonly used indicators of self reported health were selected. The first indicator was self assessed health. This indicator was measured with a single item question ("How is your health in general?") with answer possibilities on a 5 point scale: very good, good, fair, sometimes good and sometimes bad, bad. For this study two cut off points were used: "less than good" and "less than fair health".

The second indicator was the prevalence of short-term limitations during the past 14 days. This indicator measured whether a person had to cut down on the things they usually do because of an illness or injury.

The third indicator was the prevalence of one or more chronic diseases. The prevalence of two or more chronic diseases was also measured. The respondents were asked to tick on a list for each chronic disease separately which of the 24 chronic diseases they had. The list of chronic diseases used to be part of an oral interview but went over in 1994 to the paper version of the survey. Hypertension was excluded from the analyses of the chronic diseases, because it is a risk factor rather than a chronic disease.

The fourth indicator was the prevalence of one or more long term health problems. This was based on an open-ended question with yes or no as response categories. The question was "Do you have one or more long term illness(es), disorder(s) or handicap(s)?" Because there were subsequent questions on any additional long term health problem (up to a maximum of four problems), the prevalence of two or more long term health problems could also be determined. This prevalence was also measured in this study.

The third and the fourth indicator could only be analysed for the years 1989 to 1999 .

\section{Socioeconomic indicators}

Because of methodological problems with occupational class as socioeconomic indicator, ${ }^{16}$ this study used education and income to determine the socioeconomic status. The advantages of education and income as socioeconomic indicators are that they are measurable for both men and women, and for all age groups. Problems arise when the occupational class has to be determined for women or elderly people, many of whom were economically inactive in the Netherlands. Another advantage of using both education and income is that they are complementary in several ways. Firstly, while income emphasises the material component of socioeconomic status, education rather reflects the cultural or behavioural component. Secondly, while income is a measure that is variable over time because of, for example, the changing of jobs or retirement, educational attainment is nearly stable over the entire adult life. Finally, income is (at least in this study) measured at the household level, while education is individually determined.

Education was measured according to the highest completed educational level. Persons still attending school were classified according the educational level of the school they attended. Four groups were used (with Dutch abbreviations between brackets): primary school; lower secondary and vocational education (MAVO\&LBO); upper secondary and middle vocational education (HAVO, VWO \& MBO); and tertiary education (HBO \& University).

For income, the household equivalent income was measured. This was done by summing the net year income of all household members and adjusting this sum for the square root of the household size. For each period separately, and for men and women separately, the population was divided into quintiles based on the household equivalent income.

The non-response to survey questions on income was about $20 \%$ in both the NethHIS and the POLS. In the discussion section, we will answer the question to what extent this response problem may have biased the results.

\section{Analysis}

For the analysis, the data from individual years were pooled into five time periods: 1981-1984, 1985-1988, 1989-1992, 1993-1996, and 1997-1999. For each period, prevalence rates were calculated. These rates were age adjusted to five year age groups according to the direct method with the age distribution of 1 January 1997 as the standard. Men and women were analysed separately.

For each period separately, the magnitude of health inequalities between socioeconomic groups was measured by calculating the following inequality indices: the rate difference, the odds ratio (with $95 \%$ confidence intervals) and the relative index of inequality (RII) (with 95\% confidence intervals).

The rate difference measures the absolute difference in prevalence rates between the lowest socioeconomic group (primary school or lowest income quintile) and highest group 
Table 1 Population distribution by sex and educational level in the Netherlands, 1981-1999

\begin{tabular}{|c|c|c|c|c|c|c|}
\hline \multirow{2}{*}{$\begin{array}{l}\text { Sex and educational } \\
\text { level }\end{array}$} & \multicolumn{5}{|l|}{$\mathrm{N}(\%)$} & \multirow{2}{*}{$\begin{array}{l}\text { Trend (difference } \\
\text { between } \% \text { in first and } \\
\text { last period) }\end{array}$} \\
\hline & 1981-1984 & 1985-1988 & 1989-1992 & 1993-1996 & 1997-1999 & \\
\hline \multicolumn{7}{|l|}{ Men } \\
\hline I (low) & 3031 (22.1) & $2306(18.4)$ & $2126(18.1)$ & 2413 (18.2) & 1677 (15.6) & -6.5 \\
\hline$\|$ & 4069 (29.7) & $3278(26.1)$ & 2747 (23.3) & 3071 (23.1) & $2380(22.2)$ & -7.6 \\
\hline III & 4335 (31.7) & 4645 (37.0) & 4497 (38.2) & 4766 (35.9) & 4045 (37.7) & +6.0 \\
\hline IV (high) & 2256 (16.5) & 2327 (18.5) & $2400(20.4)$ & $3016(22.7)$ & 2641 (24.6) & +8.1 \\
\hline Total & 13691 (100) & $12556(100)$ & $11770(100)$ & $13266(100)$ & $10743(100)$ & \\
\hline \multicolumn{7}{|l|}{ Women } \\
\hline I (low) & 4480 (31.5) & 3552 (26.9) & 3311 (26.5) & 3725 (26.2) & 2588 (22.8) & -8.7 \\
\hline$\|$ & 4705 (33.1) & 4301 (32.5) & 3567 (28.5) & 3865 (27.2) & 3239 (28.5) & -4.5 \\
\hline III & $3550(25.0)$ & 3659 (27.7) & $3848(30.8)$ & $4414(31.1)$ & $3559(31.4)$ & +6.4 \\
\hline IV (high) & $1484(10.4)$ & 1704 (12.9) & 1780 (14.2) & $2190(15.4)$ & 1961 (17.3) & +6.8 \\
\hline Total & $14219(100)$ & $13216(100)$ & $12506(100)$ & $14194(100)$ & 11347 (100) & \\
\hline
\end{tabular}

(tertiary education or highest income quintile). The odds ratio is the ratio of the odds of having the disease in the lowest compared with the highest socioeconomic group. The rate difference and the odds ratio were chosen because they are simple to interpret and because they are complementary as they measure health inequalities in both absolute and relative terms. ${ }^{2}{ }^{17}$

The RII is an odds ratio that can be interpreted as the ratio of the odds of having the disease for those in the lowest social economic group compared with those in the highest social economic group. This measure was chosen because it has the advantages over the "normal" odds ratio that it takes into account the differences between each socioeconomic group separately, and also takes into account the distribution of the population over these socioeconomic groups. This is important as for education the distribution of the population (especially women) over the educational levels is not constant over time. Also with the RII, only health differences that are systematically related to the socioeconomic groups are measured. ${ }^{2}{ }^{17}$ For the calculation of the RII, the socioeconomic status of each group was quantified as the relative position of that group in the socioeconomic hierarchy. This continuous measure of socioeconomic status was related to the prevalence rates of the health indicators by means of logistic regression. Adjustment for age was made by including an ordinal variable representing five year age groups into the model.

There are two ways to look at trends over time: look at "trends in inequalities" or look at "inequalities in trends". The first approach is the principal one pursued in this paper. We studied "trends in inequalities" by comparing the five periods with regard to the above described inequality indices (rate difference, odds ratio, and RII). On the basis of these comparisons we determined whether inequalities were increasing, decreasing or stable.

The second approach, looking at "inequalities in trends", was used in this study in a supplementary way. For each socioeconomic group separately, we determined trends over time in the prevalence rates. This was done by calculating slope estimates that represent for each group separately the per period percentage change in the prevalence rates. These estimates were obtained by applying logistic regression models with control for age. By comparing the slope estimates (with their 95\% confidence intervals) for the different socioeconomic groups it could be determined if there was inequality in the trends.

All the analyses were done with the SPSS (version 8) statistical package.

\section{RESULTS}

Table 1 shows the distribution of the population according to educational level. For both men and women the number of persons in the lowest educational groups decreased over time, while the number of persons in the highest educational groups increased.

Table 2 displays information on the income distribution of men and women in the five periods. For both men and women, the ratio between the income of the 20th centile and the 80th centile remained about the same over time. Similarly, the trend over time in income levels (expressed by the ratio

Table 2 Income percentile values for the Netherlands, 1981-1999

\begin{tabular}{|c|c|c|c|c|c|c|}
\hline \multirow[b]{2}{*}{ Sex and centile } & \multicolumn{5}{|c|}{ Household equivalent income (in guilders) } & \multirow{2}{*}{$\begin{array}{l}\text { - Trend (ratio between } \\
\text { the last and first period) }\end{array}$} \\
\hline & $1981-1984$ & 1985-1988 & 1989-1992 & 1993-1996 & 1997-1999 & \\
\hline \multicolumn{7}{|l|}{ Men } \\
\hline p20 & 10785 & 11752 & 13678 & 16065 & 19516 & 1.81 \\
\hline 40 & 13678 & 15252 & 17352 & 21252 & 26451 & 1.93 \\
\hline p60 & 16996 & 19343 & 23690 & 26872 & 33928 & 2.00 \\
\hline 80 & 23690 & 26872 & 34643 & 38909 & 44292 & 1.87 \\
\hline Ratio $20 / p 80$ & 0.46 & 0.44 & 0.39 & 0.41 & 0.44 & \\
\hline \multicolumn{7}{|l|}{ Women } \\
\hline p20 & 10785 & 11549 & 13678 & 15252 & 17410 & 1.61 \\
\hline 40 & 14144 & 15028 & 17033 & 20414 & 23743 & 1.68 \\
\hline p60 & 16752 & 19002 & 23502 & 26834 & 30947 & 1.85 \\
\hline 80 & 23690 & 26834 & 32884 & 35519 & 41292 & 1.74 \\
\hline Ratio ${ }_{p} 20 / p 80$ & 0.46 & 0.43 & 0.42 & 0.43 & 0.42 & \\
\hline
\end{tabular}


Table 3 Prevalence of "less than good" health according to educational level in the Netherlands, 1981-1999

\begin{tabular}{|c|c|c|c|c|c|c|}
\hline \multirow{2}{*}{$\begin{array}{l}\text { Sex and educational } \\
\text { level }\end{array}$} & \multicolumn{5}{|c|}{ Prevalence rate (per 100 respondents) } & \multirow{2}{*}{$\begin{array}{l}\text { Trend slope estimate } \\
(95 \% \mathrm{CI})\end{array}$} \\
\hline & $1981-1984$ & $1985-1988$ & 1989-1992 & 1993-1996 & 1997-1999 & \\
\hline \multicolumn{7}{|l|}{ Men } \\
\hline I (low) & 33.1 & 27.2 & 31.5 & 30.6 & 34.9 & 1.01 (0.98 to 1.04$)$ \\
\hline$\|$ & 22.5 & 21.1 & 22.3 & 21.5 & 21.2 & $0.98(0.95$ to 1.01$)$ \\
\hline III & 17.8 & 15.9 & 17.2 & 17.0 & 17.4 & 1.01 (0.98 to 1.03$)$ \\
\hline IV (high) & 13.2 & 11.3 & 10.9 & 11.5 & 11.8 & $0.98(0.94$ to 1.02$)$ \\
\hline Total & 21.8 & 18.5 & 19.7 & 19.3 & 19.6 & \\
\hline Rate difference & 19.9 & 16.0 & 20.6 & 19.1 & 23.2 & \\
\hline Odds ratio $(95 \% \mathrm{CI})$ & $\begin{array}{l}3.41 \\
(2.91 \text { to } 3.99)\end{array}$ & $\begin{array}{l}3.14 \\
(2.64 \text { to } 3.74)\end{array}$ & $\begin{array}{l}4.00 \\
(3.38 \text { to } 4.74)\end{array}$ & $\begin{array}{l}3.57 \\
(3.07 \text { to } 4.14)\end{array}$ & $\begin{array}{l}3.87 \\
(3.29 \text { to } 4.55)\end{array}$ & \\
\hline $\operatorname{RII}(95 \% \mathrm{CI})$ & $\begin{array}{l}4.53 \\
(3.83 \text { to } 5.35)\end{array}$ & $\begin{array}{l}3.83 \\
\text { (3.20 to } 4.59)\end{array}$ & $\begin{array}{l}5.10 \\
(4.25 \text { to } 6.12)\end{array}$ & $\begin{array}{l}4.60 \\
(3.89 \text { to } 5.44)\end{array}$ & 4.82 & \\
\hline \multicolumn{7}{|l|}{ Women } \\
\hline I (low) & 32.1 & 30.8 & 33.3 & 33.7 & 38.2 & 1.06 (1.04 to 1.09 ) \\
\hline II & 23.8 & 22.1 & 23.8 & 23.7 & 26.7 & 1.04 (1.01 to 1.06$)$ \\
\hline III & 19.7 & 18.3 & 19.3 & 21.8 & 23.3 & 1.06 (1.03 to 1.09 ) \\
\hline IV (high) & 20.1 & 16.8 & 15.8 & 17.7 & 17.3 & 1.01 (0.97 to 1.05$)$ \\
\hline Total & 25.0 & 22.7 & 23.8 & 24.8 & 26.6 & \\
\hline Rate difference & 12.0 & 14.1 & 17.6 & 16.0 & 21.0 & \\
\hline Odds ratio $(95 \% \mathrm{CI})$ & $\begin{array}{l}2.04 \\
(1.73 \text { to } 2.41)\end{array}$ & $\begin{array}{l}2.37 \\
(2.00 \text { to } 2.80)\end{array}$ & $\begin{array}{l}2.74 \\
(2.32 \text { to } 3.24)\end{array}$ & $\begin{array}{l}2.60 \\
(2.24 \text { to } 3.00)\end{array}$ & $\begin{array}{l}3.05 \\
(2.61 \text { to } 3.57)\end{array}$ & \\
\hline $\operatorname{RII}(95 \% \mathrm{CI})$ & $\begin{array}{l}2.66 \\
(2.26 \text { to } 3.13)\end{array}$ & $\begin{array}{l}3.03 \\
(2.55 \text { to } 3.60)\end{array}$ & $\begin{array}{l}3.71 \\
(3.11 \text { to } 4.42)\end{array}$ & $\begin{array}{l}3.19 \\
(2.71 \text { to } 3.74)\end{array}$ & $\begin{array}{l}3.90 \\
(3.27 \text { to } 4.65)\end{array}$ & \\
\hline
\end{tabular}

between the last and first period) is about the same for each income quintile. During the 1990s, within each income quintile, the income of women improved less than the income of men.

As illustrative examples of the observed trends in health inequalities in the Netherlands in the period 1981-1999, tables 3 and 4 show the results for less than good self assessed health.

Table 3 shows, for each sex and each period separately, the prevalence of less than good self assessed health by educational level. In each case, prevalence rates are highest in the lowest educational level. For men there is no clear increase or decrease over time in the magnitude of inequalities in less than good health. Also, prevalence rates are stable over time in each socioeconomic group. For women both the rate difference, the odds ratio and the RII indicate increasing socioeconomic differences. The slope estimate in the last column shows that this increase is the result of a slightly increasing prevalence of less than good health in all socioeconomic groups except the highest.

Table 4 Prevalence of "less than good" health according to income level in the Netherlands, 1981-1999

\begin{tabular}{|c|c|c|c|c|c|c|}
\hline \multirow{2}{*}{$\begin{array}{l}\text { Sex and income } \\
\text { level }\end{array}$} & \multicolumn{5}{|c|}{ Prevalence rate (per 100 respondents) } & \multirow{2}{*}{$\begin{array}{l}\text { Trend slope } \\
\text { estimate }(95 \% \mathrm{Cl})\end{array}$} \\
\hline & $1981-1984$ & $1985-1988$ & 1989-1992 & 1993-1996 & 1997-1999 & \\
\hline \multicolumn{7}{|l|}{ Men } \\
\hline I (low) & 30.9 & 27.3 & 29.8 & 32.0 & 31.9 & $1.03(1.00$ to 1.06$)$ \\
\hline$\|$ & 26.8 & 21.9 & 23.3 & 23.4 & 21.9 & $0.95(0.91$ to 0.98$)$ \\
\hline III & 23.7 & 17.6 & 21.3 & 19.2 & 18.3 & $0.93(0.89$ to 0.96$)$ \\
\hline IV & 18.4 & 17.0 & 16.4 & 14.9 & 14.6 & $0.92(0.88$ to 0.95$)$ \\
\hline V (high) & 14.5 & 11.9 & 11.3 & 10.8 & 11.4 & $0.92(0.86$ to 0.96$)$ \\
\hline Total & 22.9 & 19.2 & 20.3 & 19.9 & 19.6 & \\
\hline Rate difference & 16.4 & 15.4 & 18.5 & 21.2 & 20.5 & \\
\hline Odds ratio $(95 \% \mathrm{Cl})$ & $\begin{array}{l}2.80 \\
(2.38 \text { to } 3.29)\end{array}$ & $\begin{array}{l}3.16 \\
(2.64 \text { to } 3.80)\end{array}$ & $\begin{array}{l}3.70 \\
(3.06 \text { to } 4.47)\end{array}$ & $\begin{array}{l}4.23 \\
(3.72 \text { to } 5.27)\end{array}$ & $\begin{array}{l}4.05 \\
\text { (3.36 to } 4.87)\end{array}$ & \\
\hline $\operatorname{RII}(95 \% \mathrm{Cl})$ & $\begin{array}{l}3.58 \\
(3.00 \text { to } 4.28)\end{array}$ & $\begin{array}{l}3.63 \\
(2.98 \text { to } 4.41)\end{array}$ & $\begin{array}{l}4.42 \\
(3.62 \text { to } 5.40)\end{array}$ & $\begin{array}{l}5.89 \\
(4.88 \text { to } 7.12)\end{array}$ & $\begin{array}{l}5.60 \\
(4.56 \text { to } 6.87)\end{array}$ & \\
\hline \multicolumn{7}{|l|}{ Women } \\
\hline I (low) & 31.1 & 28.7 & 28.2 & 34.8 & 36.9 & $1.08(1.05$ to 1.11$)$ \\
\hline$\|$ & 29.2 & 26.0 & 26.5 & 25.4 & 32.7 & 1.04 (1.00 to 1.07$)$ \\
\hline III & 26.1 & 24.5 & 25.0 & 23.7 & 25.8 & $0.99(0.95$ to 1.02$)$ \\
\hline IV & 25.2 & 21.2 & 21.1 & 23.5 & 23.4 & 0.98 (0.95 to 1.02$)$ \\
\hline V (high) & 19.8 & 17.3 & 17.2 & 18.5 & 18.0 & $0.99(0.95$ to 1.03$)$ \\
\hline Total & 26.5 & 23.4 & 23.6 & 25.4 & 27.4 & \\
\hline Rate difference & 11.3 & 11.4 & 11.0 & 16.3 & 18.9 & \\
\hline Odds ratio $(95 \% \mathrm{Cl})$ & $\begin{array}{l}1.89 \\
(1.63 \text { to } 2.19)\end{array}$ & $\begin{array}{l}2.10 \\
(1.79 \text { to } 2.47)\end{array}$ & $\begin{array}{l}1.95 \\
(1.65 \text { to } 2.30)\end{array}$ & $\begin{array}{l}2.55 \\
(2.21 \text { to } 2.95)\end{array}$ & $\begin{array}{l}2.81 \\
(2.38 \text { to } 3.32)\end{array}$ & \\
\hline RII $(95 \% \mathrm{Cl})$ & $\begin{array}{l}2.02 \\
(1.72 \text { to } 2.38)\end{array}$ & $\begin{array}{l}2.30 \\
(1.94 \text { to } 2.74)\end{array}$ & $\begin{array}{l}2.27 \\
(1.90 \text { to } 2.72)\end{array}$ & $\begin{array}{l}2.92 \\
(2.47 \text { to } 3.44)\end{array}$ & $\begin{array}{l}3.66 \\
(3.05 \text { to } 4.41)\end{array}$ & \\
\hline
\end{tabular}


Table 5 Overview of the trends in health inequalities according to education. Men and women separately

\begin{tabular}{|c|c|c|c|c|c|c|}
\hline \multirow[b]{2}{*}{ Sex and health indicator } & \multicolumn{5}{|c|}{ RII (change to previous period) } & \multirow{2}{*}{$\begin{array}{l}\text { Trend between the } \\
\text { first and last period }\end{array}$} \\
\hline & $81-84$ & $85-88$ & $89-92$ & $93-96$ & $97-99$ & \\
\hline \multicolumn{7}{|l|}{ Men } \\
\hline Less than good health & 4.53 & $3.83(-)$ & $5.101+1$ & $4.60(-)$ & $4.82(0)$ & 0 \\
\hline Less than fair health & 6.64 & $4.65(-)$ & $6.25(+)$ & $5.04(-)$ & $6.40(+)$ & 0 \\
\hline Short-term disabilities & 1.59 & $1.92(0)$ & $2.14(0)$ & $1.89(0)$ & $1.53(0)$ & 0 \\
\hline One or more chronic diseases & & & 1.99 & $1.93(0)$ & $1.63(0)$ & 0 \\
\hline Two or more chronic diseases & & & 2.75 & $2.53(0)$ & $2.36(0)$ & 0 \\
\hline One or more longstanding health problem & & & 2.21 & $2.41(0)$ & $2.24(0)$ & 0 \\
\hline Two or more longstanding health problems & & & 2.59 & $2.20(0)$ & $2.46(0)$ & 0 \\
\hline \multicolumn{7}{|l|}{ Women } \\
\hline Less than good health & 2.66 & $3.03(0)$ & $3.71(+)$ & $3.19(-)$ & $3.90(+)$ & $+^{*}$ \\
\hline Less than fair health & 2.71 & $3.68(+)$ & $3.77(0)$ & $3.02(-)$ & $4.35(+)$ & + \\
\hline Short-term disabilities & 1.22 & $1.28(0)$ & $1.34(0)$ & $1.31(0)$ & $1.22(0)$ & 0 \\
\hline One or more chronic diseases & & & 1.35 & $1.45(0)$ & $1.22(0)$ & 0 \\
\hline Two or more chronic diseases & & & 1.52 & $1.76(0)$ & $1.53(0)$ & 0 \\
\hline One or more longstanding health problem & & & 1.49 & $1.83(0)$ & 1.49 (0) & 0 \\
\hline Two or more longstanding health problems & & & 1.67 & $2.11(0)$ & $1.49(-)$ & 0 \\
\hline
\end{tabular}

Table 4 shows the prevalence of less than good self assessed health according to income quintiles. For each sex and each period, the prevalence rate of less than good health is higher in the lower income quintiles. The rate difference, odds ratio and RII show that for women, especially in the early 1990s, income related health inequalities increased. For men, income related health inequalities increased in this period as well. These increases resulted from a decrease in prevalence rate in the highest income groups in the case of men, and from an increase in the prevalence rate in the lowest income group in the case of women. The slope estimates in the last column show a marked contrast between, on the one hand, rising prevalence rates in the lowest income quintiles of men and in the two lowest quintiles of women and, on the other hand, declining prevalence rates in all higher income quintiles.

Tables 5 and 6 present overviews in which trends over time are shown for all health indicators included in this study. These tables concern health inequalities according to education and income respectively. By means of "+" and " - " signs, comparisons are made between RIIs of subsequent periods, and also between the RIIs of the first and the last period.

Here the results are shown according to the RII, because this is the most appropriate measure for analysing the trends over time (see methods section). Similar trends were obtained in terms of odds ratios.

In general, taking the whole study period into consideration, there is no consistent trend towards an increase or a decrease in health inequalities. In some cases, most often for income related health inequalities, inequalities increased over time, while in all other cases inequalities were more or less stable. For education as an socioeconomic indicator, inequalities in health remained more or less constant over time.

Different trends are observed for the different health indicators. Inequalities in self assessed health (measured as "less than good" and "less than fair health") showed a fairly consistent increase over time. Inequalities in the other health indicators remained more or less constant over time. For some health indicators, however, a temporary increase in income related health inequalities occurred in the early 1990s.

Men and women show somewhat different trends. Among women there is more often a significant increase over time in socioeconomic inequalities in health.

Comparisons of separate periods show that the trends in socioeconomic inequalities vary between the different periods. For example, income related inequalities in health increased

Table 6 Overview of the trends in health inequalities according to income. Men and women separately

\begin{tabular}{|c|c|c|c|c|c|c|}
\hline \multirow[b]{2}{*}{ Sex and health indicator } & \multicolumn{5}{|c|}{ RII (change compared with previous period) } & \multirow{2}{*}{$\begin{array}{l}\text { - Trend between the } \\
\text { first and last period }\end{array}$} \\
\hline & $81-84$ & $85-88$ & 89-92 & $93-96$ & $97-99$ & \\
\hline \multicolumn{7}{|l|}{ Men } \\
\hline Less than good health & 3.58 & $3.63(0)$ & $4.42(+)$ & $5.89(+)$ & $5.60(0)$ & $+^{*}$ \\
\hline Less than fair health & 4.30 & $4.68(0)$ & $6.47 i+1$ & $5.71(-)$ & $8.28 i+1$ & $+{ }^{*}$ \\
\hline Short-term disabilities & 1.28 & 1.44 (0) & $1.85(0)$ & $2.13(0)$ & $1.60(-)$ & 0 \\
\hline One or more chronic diseases & & & 1.69 & $1.86(0)$ & $1.53(0)$ & 0 \\
\hline Two or more chronic diseases & & & 2.48 & $3.101+1$ & $2.37(-)$ & 0 \\
\hline One or more longstanding health problem & & & 1.95 & $2.481+1$ & $1.81(-)$ & 0 \\
\hline Two or more longstanding health problems & & & 2.86 & $3.95 i+1$ & $2.50(-)$ & 0 \\
\hline \multicolumn{7}{|l|}{ Women } \\
\hline Less than good health & 2.02 & $2.30(0)$ & $2.27(0)$ & $2.92(+)$ & $3.66(+)$ & $+^{*}$ \\
\hline Less than fair health & 2.11 & $2.64(+)$ & $2.54(0)$ & $3.15 i+1$ & $4.66(+)$ & $+^{*}$ \\
\hline Short-term disabilities & 0.91 & $1.24(0)$ & $1.03(0)$ & $1.29(0)$ & $1.32(0)$ & 0 \\
\hline One or more chronic diseases & & & 1.16 & $1.56(0)$ & $1.26(0)$ & 0 \\
\hline Two or more chronic diseases & & & 1.42 & $1.95 i+1$ & $1.72(0)$ & 0 \\
\hline One or more longstanding health problem & & & 1.21 & $1.69(0)$ & $1.65(0)$ & 0 \\
\hline Two or more longstanding health problems & & & 1.52 & $2.27(+1$ & $1.71(-)$ & 0 \\
\hline
\end{tabular}


especially in the early 1990s (between 1989-92 and 1993-96) and much less in the 1980s and late 1990s.

\section{DISCUSSION \\ Summary of the results}

The results for each of the periods show that, as already is known, socioeconomic inequalities exist for each of the health indicators, for both men and women, and for income and education. These inequalities have also been found in former studies with data from the Netherlands' Health Interview Survey. ${ }^{917}$ With this study, health inequalities could for the first time also be demonstrated for the last years of the 20th century. In addition, trends over a longer period of time, 19 years, could be investigated for both education and income as socioeconomic indicators and for each of the four indicators of self reported health.

Looking at the observed trends, the first impression is one of stability: inequalities in health persisted with approximately the same magnitude during the 1980s and 1990s. In none of the cases did these inequalities show a clear tendency to diminish. In some cases, however, there was strong evidence for a substantial increase in socioeconomic inequalities in self reported health. This increase was most pronounced for women and when income was used as the socioeconomic indicator.

As mentioned in the introductory part of this paper, past studies on trends in socioeconomic inequalities in self assessed health obtained inconsistent results. This variability is also present in our study. The trends that we found depended upon several factors including the sex of the respondent, the socioeconomic indicator that was used, the health indicator that was looked at, and the periods that were taken into consideration.

\section{Explanations}

In agreement with other studies, the general picture is one of persistent socioeconomic health inequalities. ${ }^{13-68}$ This finding underlines how strongly socioeconomic health inequalities are embedded in modern society. Against the background of this persistency it is of interest to study patterns of change in the magnitude of socioeconomic inequalities in health and to speculate about possible explanations for these changes.

When income was used as the socioeconomic indicator, inequalities in self assessed health showed a substantial and statistically significant increase over time. An important question is how these increases can be explained. Answering this question will not be easy, given the fact that it is already difficult to explain income related inequalities in health at one point in time.

\section{Artefact}

A first possible "explanation" of the observed increases in income related health inequalities is that the observed trends are an artefact, because of weaknesses of the study methods and research instruments.

The first weakness of our study relates to the non-response, which was not only high (34\% in the beginning of the 1980s) but also increased over time (to $42 \%$ in the end of the 1990s).

According to research from Statistics Netherlands, nonresponse rates did not differ according to sex. ${ }^{18}$ There is however some evidence that the non-response is generally higher in the lower socioeconomic groups and higher among the less healthy. ${ }^{19}{ }^{21}$ These associations could result in an underestimation of socioeconomic inequalities in health. As the total nonresponse showed an increase over time, the underestimation could have been larger for later periods than for the beginning. This would have had the effect that the widening of inequalities, which we observed for self assessed health, could have been underestimated. Thus, the increases observed in this study might in reality have been even more pronounced and there might have been increases where our study found stability over time. We should add, however, that research from Statistics Netherlands indicates that non-response rates are only weakly related to income. ${ }^{18}$

The second potential data problem is that people living in nursing homes, homes for the elderly people, and institutions for physically and mentally handicapped people were excluded from the surveys. Their exclusion could bias the results if the chance of becoming institutionalised is not only related to the physical or mental state of health but also to socioeconomic status. However, as only about $2 \%$ of the national population is excluded from the survey because of being institutionalised, ${ }^{14}$ the effect on the results of their exclusion is probably to be small.

Thirdly, non-native Dutch speakers and those not registered in the municipal record are underrepresented in the surveys. This concerns mainly immigrants and refugees. In general, these groups are of a lower socioeconomic status and there are indications that they experience a worse health compared with the Dutch population. ${ }^{22-24}$ Poor health is not merely a cause of their lower socioeconomic status. As the number of immigrants and especially refugees is rising in the Netherlands, the observed increase in socioeconomic inequalities in self assessed health could have been underestimated.

Fourthly, problems with the measurement of income could have biased the results. For income, the partial non-response rate is about $20 \%$ during the whole research period. In additional analysis, we assessed the extent to which the results could have been biased by the exclusion of respondents whose income was unknown. We observed that non-response is not strongly related to education (with slightly higher response in the highest educational group) and neither related to health indicators. Given these weak associations, we concluded that the results are probably not biased to any important extent by the non-response on income.

Another problem with income could be that persons do not report their income accurately. Inaccurate reporting of income may lead to misclassification bias, which probably results in underestimation of the magnitude of income related health inequalities. It is uncertain, however, whether this bias is substantial and, in addition, whether it changed over time.

Fifthly, problems could occur with respect to the measurement of the health indicators. The answer categories to the question concerning self assessed health have changed. In 1981 and 1982, it was not possible to make the distinction between good and very good health. In additional analysis, we evaluated whether the exclusion of these two years would change the results for the first study period (1981-1984). We found that the inequality estimates were not sensitive to the inclusion or exclusion of the first two years.

The change in the way of presenting the questions on chronic diseases, from oral interview until 1993 to the paper and pencil method since 1994 (see methods section) is more difficult to evaluate. An inspection of overall prevalence rates during these years suggested that the change in method did not have large effects on the reporting of chronic conditions.

A potentially important problem is that the reporting of a health problem not only depends on the presence of an "objective" health problem but also on the respondents' perception of the health problem, the knowledge about this problem, the consequences of illness for everyday life, and the propensity to complain. A Dutch study indicated that respondents who are lower educated are less inclined to, or more often fail to, report chronic diseases like diabetes mellitus, chronic non-specific lung disease, and especially heart disease. ${ }^{25}$ In our study this could lead to an underestimation of socioeconomic inequalities in the prevalence of chronic conditions. If this and other aspects of the respondents' reporting behaviour changes over time, then this may have biased the observed trends in socioeconomic inequalities in self reported health. Unfortunately, there is no way to check whether this bias is substantial or negligible. 


\section{Key points}

- In general, socioeconomic inequalities in self reported health in the Netherlands persisted with about the same magnitude during the 1980s and 1990s.

- Increases were observed for a few cases and in particular for income related inequalities in self assessed health.

- For no health or socioeconomic indicator, a decrease in health inequalities was observed.

- Several factors (including smoking and working conditions) may have contributed to the increase in income related inequalities in self assessed health.

- This increase was probably especially attributable to new labour market policies in the beginning of the 1990s, which caused the income position of sick persons to deteriorate.

To conclude, several potential data problems might have biased to some extent the observed socioeconomic inequalities in health indicators. An underestimation of these inequalities is most probably to have resulted from these biases. It is uncertain whether the magnitude of the bias has changed over time. All these factors together cannot explain why there is a widening in the inequalities especially in self assessed health and why increases in health inequalities have been especially observed for income rather than for education, and for women rather than men. We think that other explanations need to be considered as well.

\section{Selection}

A second type of explanation relates to the selection mechanism - that is, the fact that health itself could have an effect on socioeconomic status-for example, by means of health related social mobility. When education is used as the socioeconomic indicator, the influence of selection effects is probably small. On the other hand, with income this effect might play an important part that in addition changes over time.

The strong and sudden increase in income related health inequalities in the beginning of the 1990s might perhaps be because of changes in the income position of those who were incapacitated for work. Research from the Netherlands has shown that health selection processes are operative especially with respect to entry and exit from the labour market rather than the position within the labour market. ${ }^{26}$ In the beginning of the 1990s, new regulations were introduced as a result of which employers became responsible for the cost of absence attributable to their employees' illness. This could have led to an increased selection on health at entry into the labour market. ${ }^{27}$ These measures were however turned down in 1998, when the Dutch government banned the general medical examination for employing people. It is perhaps not accidental that parallel developments occurred in income related inequalities in some health indicators, which increased in the early 1990s and decreased again in the late 1990s.

Selection processes could also be operative in other ways, for example, via the level of disablement benefits. In 1994-1997, the Dutch government introduced new policy measures that aimed to reduce the number of people entitled to a disablement benefit. The measures included a restriction of the criteria for awarding such benefit and a reduction of benefits for those with prolonged work disability. ${ }^{27}$ These measures may have had the effect to strengthen the association between income and ill health, because some of the long term disabled were no longer eligible for a generous disability benefit but, instead, came to rely on the lower benefits administered by social welfare.

A last way in which the selection process could be operative is through unemployment. When unemployment is comparatively low the unemployed tend to be less alike the employed. ${ }^{528}$ This could lead to larger socioeconomic health inequalities, because in such periods especially the less healthy rely on social benefits. The decrease in the unemployment rate in the Netherlands over the study period (from 11\% in the early 1980s and $4 \%$ in the late 1990s) could in this way have contributed to the increase in the income related health inequalities.

\section{Causation}

The last type of explanation of the widening income related health inequalities relates to the social causation mechanism - that is, the effect that the education or income level of respondents can have on their health through specific determinants of health and illness. These determinants are traditionally divided in material or structural factors and behavioural factors.

Research on trends in health inequalities has until now concentrated mostly on behavioural factors. A much investigated factor is smoking. A similar study conducted by our team on the trends in socioeconomic differences in risk factors has shown that especially among women, socioeconomic differences in smoking prevalence increased during the 1990 s. $^{29}$ Previous studies demonstrated that this was part of a long term trend in the Netherlands, as well as in other Northern European countries, in which smoking rates developed least favourably in lower socioeconomic groups. ${ }^{30-33}$ As smoking is related to a great number of health problems it may be expected that this factor has contributed (with some lag time) to the increase in socioeconomic inequalities in some of the health indicators considered in our study. In additional analysis of specific chronic conditions, we observed that socioeconomic inequalities among women increased in particular for heart disease..$^{29}$ In addition to smoking, other behavioural risk factors related to heart disease, such as physical activity and dietary habits, may have contributed to this trend. However, for one of these factors, overweight, we observed that socioeconomic inequalities in prevalence rates decreased during the 1980s and 1990s. ${ }^{29}$

In addition to health related behavioural factors, working conditions could also have contributed to the widening of inequalities in self assessed health. Over the study period, work related stress increased in the Netherlands. Data from Statistics Netherlands show that an important aspect of work related stress, the experienced time pressure among the working population, has shown a tendency to increase. ${ }^{34}$ It is known that in general the employees of the lower social classes are more vulnerable to work related stress, because their lower control over work load and time schedule gives them less opportunities to cope with this stress. ${ }^{35}$ Hence, it can be argued that in particular the lower social classes will experience more health complaints from this rise in work related stress.

As health inequalities increased more markedly according to income than education it is probable that factors related to material living conditions have contributed to the observed increases. Research from the Netherlands has shown that the financial problems probably can explain a large part of the socioeconomic differences in health at one point in time. ${ }^{36}{ }^{37} \mathrm{It}$ is uncertain if financial problems have also contributed to the increase in the socioeconomic inequalities over time. It is often suggested that the size of income inequalities may be an important determinant of the health of populations, and of the lower groups in particular. ${ }^{38}$ In our study period, however, in accordance with other Dutch data, ${ }^{40}$ the relative differences in income between the highest and lowest income quintiles remained about the same. The absolute income differences between the highest and the lowest income quintile on the contrary broadened over the study period. This increase could perhaps have contributed to the increase in income related socioeconomic health inequalities.

In conclusion, there are several possible explanations for the fact that, in addition to stable health inequalities in general, 
income related inequalities in some health indicators increased in the Netherlands, especially in the early 1990s. The relative importance of these explanations has yet to be determined. The fact that socioeconomic inequalities in health increased especially among women may be especially attributable to trends in behavioural factors such as smoking. In general, perhaps most influential were selection effects, related to changing labour market policies in the Netherlands.

\section{ACKNOWLEDGEMENTS}

We thank Wim A Zweekhorst for his comments on previous versions of this paper.

\section{Disclaimer}

The views expressed in this paper are those of the authors and do not necessarily reflect the opinions of Statistics Netherlands.

\section{Authors' affiliations}

J A A Dalstra, A E Kunst, J P Mackenbach, Department of Public Health, Erasmus University Rotterdam, Netherlands

J J M Geurts, F J M Frenken, Statistics Netherlands, Division Social and Spatial Statistics, Netherlands

Funding: this paper is written as part of a project on trends in socioeconomic differences in health and in risk factors in the Netherlands. This monitoring project was funded by the Dutch Programme Commission on Socio-Economic Health Differences, second phase.

Conflicts of interest: none.

\section{REFERENCES}

Heistaro S, Vartiainen E, Puska P. Trends in self-rated health in Finland 1972-1992. Prev Med 1996;25:625-32.

2 Kunst AE, Mackenbach JP. Measuring socioeconomic inequalities in health. Copenhagen: WHO regional office for Europe, 1994

3 Lahelma E, Rahkonen O, Berg MA, et al. Changes in health status and health behavior among Finnish adults 1978-1993. Scand J Work Environ Health 1997;23:85-90

4 Lahelma $\mathrm{E}$, Rahkonen $\mathrm{O}$, Huuhka M. Changes in the social patterning of health? The case of Finland 1986-1994. Soc Sci Med 1997:44:789-99.

5 Lahelma E, Arber S, Rahkonen $O$, et al. Widening or narrowing inequalities in health? Comparing Britain and Finland from the 1980s to 1990s. Social Health and Illness 2000;22:1 10-36.

6 Lahelma E, Kivelä K, Roos E, et al. Analysing changes of health inequalities in the nordic welfare states. Soc Sci Med 2002;55:609-25.

7 Whitehead $M$, Evandrou $M$, Haglund $B$, et al. As the health divide widens in Sweden and Britain, what's happening to access to care? BM 1997;315:1006-9.

8 Borrell C, Rue M, Pasarín I, et al. Trends in social class inequalities in health status, health-related behaviors and health services utilization in a Southern European urban area (1983-1994). Prev Med 2000;31:691-701.

9 Van Baal M. Trend data of the Health Interview Survey; Health indicators 1981-1996. [In Dutch]. Maandbericht gezondheid (CBS) 1997; 7:22-59.

10 Bartley M, Owen C. Relation between socioeconomic status, employment, and health during economic change, 1973-93. BM 1996;313:445-9.

11 Anitua C, Esnaola S. Changes in social inequalities in health in the Basque Country. J Epidemiol Community Health 2000;54:437-43.

12 Atkinson AB, Rainwater L, Smeeding TM. Income distribution in OECD countries. Paris: OECD, 1995

13 Statistics Netherlands. Netherlands Health Interview Survey 1981-1991. The Hague: SDU publishers/ CBS-publications, 1992

14 Statistics Netherlands. Netherlands Health Interview Survey 1981-1995. The Hague: SDU publishers/ CBS-publications, 1996
15 Otten F, Winkels J. Explanation of the permanent research on living conditions. [In Dutch]. Maandbericht Gezondheidsstatistiek 1998;04: 1 1-15

16 Kunst AE, Bos V, Mackenbach JP. Monitoring socio-economic inequalities in health in the European Union. Rotterdam: Erasmus University, Department of Public Health, 2000.

17 Mackenbach JP, Kunst AE. Measuring the magnitude of socio-economic inequalities in health: an overview of available measures illustrated with two examples from Europe. Soc Sci Med 1997;44:757-71.

18 Geuzinge L, van Rooijen J, Bakker B. Project SSB-Fase 2. Correction for selective non-response in personal surveys by use of information from registers. [In Dutch]. Heerlen: CBS, 1999.

19 Dengler R, Roberts H, Rushton L. Lifestyle surveys-the complete answer? J Epidemiol Community Health 1997;51:46-51.

20 Slymen DJ, Drew JA, Wright BL, et al. Item non-response to lifestyle assessment in an elderly cohort. Int J Epidemiol 1994;23:583-91.

21 Turrell G. Income non-reporting: implications for health inequalities research. J Epidemiol Community Health 2000;54:207-14.

22 Joung IMA, Kunst EA, van Imhoff E, et al. Socio-demographic variable and future health. [In Dutch]. Tiidschrift voor gezondheidswetenschappen 2001:79:21-31.

23 Mackenbach JP. Migrants, migration and health care. [In Dutch]. In: Migranten en Gezondheidszorg. Houten/Diegen: Bohn Stafleu van Loghum, 1996.

24 van Wersch SFM, Uniken Venema HP, Schulpen TWJ. The health status of foreigners. [In Dutch]. In: Volksgezondheid Toekomst Verkenningen 1997; Il Gezondheidsverschillen. Maarssen: Elsevier/De tijdstroom 1997.

25 Mackenbach JP Looman CW, van der Meer JB. Differences in the misreporting of chronic conditions, by level of education: the effect on inequalities in prevalence rates. Am J Public Health 1996;86:706-1 1

26 van de Mheen H, Stronks K, Schrijvers CT, et al. The influence of adult ill health on occupational class mobility and mobility out of and into employment in the The Netherlands. Soc Sci Med 1999:49:509-18.

27 Zweekhorst WA. Occupational medicine in the framework of social security system. [In Dutch]. Rotterdam: Erasmus University, iMGZ/Docvision, 2000

28 Martikainen PT, Valkonen T. Excess mortality of unemployed men and women during a period of rapidly increasing unemployment. Lancet 1996:348:909-12.

29 Konings-Dalstra JAA, Kunst AE, Geurts JM, et al. Monitoring of trends in socio-economic health differences in the Netherlands on the basis of the Health Interview Surveys of Statistics Netherlands: A report for the Programme commission on Socio-Economic Health differences II. [In Dutch]. Rotterdam/Heerlen: Erasmus Universiteit, iMGZ/Sector KPE CBS 2000.

30 Cavelaars AE, Kunst AE, Geurts JJ, et al. Educational differences in smoking: international comparison. BM 2000;320:1102-7.

31 Graham H. Smoking prevalence among women in the European community 1950-1990. Soc Sci Med 1996;43:243-54

32 van Reek J. Smoking behaviour in the Netherlands 1958-1982. [In Dutch]. Tijdschrift voor alcohol en drugs 1983;9:99-103.

33 Verschuren WMM, Smit HA, van Leer EM, et al. Prevalence of riskfactors for heart disease and changes in these riskfactors in the period 1987-1991. Final report Peilstationproject Hart- en vaatziekten 1987-1991. Final report Peilstationproject Hart-

34 Ministerie van Sociale Zaken en Werkgelegenheid. Arbobalans 2000. Den Haag: Opmeer Drukkerii bv, 2000.

35 Siegrist J, Peter R, Junge A, et al. Low status control, high effort at work and ischemic heart disease: prospective evidence from blue-collar men. Soc Sci Med 1990;31:1127-34.

36 Schriipers CT, Stronks K, van de Mheen HD, et al. Explaining educational differences in mortality: the role of behavioral and material factors. Am J Public Health 1999:89:535-40.

37 Stronks K, van de Mheen HD, Mackenbach JP. A higher prevalence of health problems in low income groups: does it reflect relative deprivation? J Epidemiol Community Health 1998;52:548-57.

38 Lynch JW, Davey Smith G, Kaplan GA, et al. Income inequality and mortality: importance to health of individual income, psychosocial environment, or material conditions. BM 2000;320:1200-4

39 Wilkinson RG. Socioeconomic determinants of health. Health inequalities: relative or absolute material standards? BM 1997:314:591-5.

40 Wetenschappelijke Raad voor het Regeringsbeleid. Division in perspective. [ln Dutch]. Den Haag: Sdu Uitgevers, 1996. 